\title{
Health-related variables and predictors of Health-promoting Lifestyle in cardiovascular disease patients
}

Hossein Mohsenipouya ${ }^{1}$, Fereshteh Majlessi ${ }^{2}$, Davood Shojaeizadeh ${ }^{3}$, Abbas Rahimi Foroushani ${ }^{4}$, Rahman Ghafari $^{5}$, Vali Habibi ${ }^{5}$, Azam Seyfi Makrani ${ }^{6}$

${ }^{1}$ Ph.D. Candidate, Department of Health Education and Promotion, School of Public Health, Tehran University of Medical Sciences, International Campus (TUMS- IC), Tehran, Iran

${ }^{2}$ MD, Professor, Department of Health Education and Promotion, School of Public Health, Tehran University of Medical Sciences, Tehran, Iran

${ }^{3}$ Ph.D., Professor, Department of Health Education and Promotion, School of Public Health, Tehran University of Medical Sciences, Tehran, Iran

${ }^{4}$ Ph.D., Professor, Department of Epidemiology and Biostatistics, School of Public Health, Tehran University of Medical Sciences, Tehran, Iran

${ }^{5}$ MD, Assistant Professor, Department of Cardiac Surgery, School of Medicine, Mazandaran University of Medical Sciences, Sari, Iran

${ }^{6}$ B.Sc. in Nursing, Fatemehzahra Hospital, Mazandaran University of Medical Sciences, Sari, Iran

\section{Type of article: Original}

\begin{abstract}
Introduction: The principal cause for death in the world is cardiovascular disease. Poor lifestyle is a contributing element in this regard. The objective of this study was to estimate the effects of health-related variables and lifestyle variables on the results of exercise stress tests in patients with cardiovascular disease in Iran.

Methods: The study population in this case-control study was 220 patients who were candidates for exercise stress tests in Mazandaran Province (Iran) in 2015. The patients were divided randomly into two groups based on the results of their exercise stress tests, i.e., positive (110 patients) and negative (110 patients). The data collection tool was a standard questionnaire entitled "Health promotion lifestyle profile-II." The data were analyzed using mean, standard deviation, the chi-squared test, and logistic regression by SPSS version 22 software.

Results: The risk of a positive exercise stress test increases with age. The age group above 65 was 1.049 times more at risk of a positive exercise stress test than the age group of less than 45 . The people with dyslipidemia had 1.635 times greater risk of positive exercise stress tests than the group without dyslipidemia. In addition, patients with hypertension had 1.579 times greater risk of positive exercise stress tests than the group without hypertension. The lack of individual health responsibility (Odds ratio (OR): 1.622), stress management (OR: 1.592), and physical activity (OR: 1.245) contributed more to positive exercise tests than the other risk factors.

Conclusion: Educational interventions can improve the responsibility for health, physical activity, and stress management among people with the risk of cardiovascular disease.
\end{abstract}

Keywords: cardiovascular disease; exercise stress test; health-promoting lifestyle

\section{Introduction}

One-fifth of deaths are cause by cardiovascular disease, and coronary heart disease is one of the major causes of death among people around the world. The elements that contribute to cardiovascular disease include family history, dyslipidemia, hypertension, diabetes, and smoking (1). It has been estimated that eighty-four billion U.S. dollars have been spent on cardiac disease, stroke, and diabetes in 23 developing countries from 2006 to 2015. These three diseases account for $80 \%$ of the total deaths caused by chronic diseases. Twenty-four million deaths in low- and

\section{Corresponding author:}

MD, Fereshteh Majlessi, Department of Health Education and Promotion, School of Public Health, Tehran University of Medical Sciences, Tehran, Iran. Tel: +98.2188989134, Email: dr_f_majlessi@yahoo.com

Received: December 07, 2015, Accepted: February 07, 2016, Published: April 2016

iThenticate screening: February 07, 2016, English editing: March 28, 2016, Quality control: April 06, 2016

(C) 2016 The Authors. This is an open access article under the terms of the Creative Commons Attribution-NonCommercialNoDerivs License, which permits use and distribution in any medium, provided the original work is properly cited, the use is non-commercial and no modifications or adaptations are made. 
middle-income countries could be prevented if non-communicable diseases could be reduced (2). Also, in Iran, coronary heart disease (CHD) is the main cause of mortality, morbidity, and disability (3), and, as mentioned in the latest report by World Health Organization (WHO) 2011, this disease causes about $45 \%$ of all deaths in Iran (4). In long-term epidemiology studies, the development of CHD risk factors can be controlled by a healthy lifestyle that includes appropriate behaviors, such as a prudent diet, not smoking, maintaining a healthy weight, and physical activity (5). If high-risk people modify their lifestyles and undergo therapies at the early stages, the primary prevention will turn out to be cost effective (6). People can improve their health through health-promoting behaviors (7). According to Pender's classification, health promoting behaviors include health responsibility, nutrition, physical activity, spiritual growth, interpersonal relationships, and stress management (8). Based the findings of clinical studies, changing one's lifestyle will have a positive effect on risk factors, such as smoking, hypertension, and hypercholesterolemia (9). Moreover, pharmacological therapies, such as lipid-lowering and anti-hypertensive drugs also can help decrease risk factors (10). For instance, they have been shown to reduce the risk of heart disease by 20 to $30 \%(10,11)$. The effect of pharmacological therapies on the reduction of the risk of heart disease is comparatively low compared to lifestyle changes (12). However, the lack of knowledge concerning how to manage the disease and the lack of family support result unsuccessful attempts to modify lifestyles among the majority of patients (13). Despite many references to the importance and efficiency of intervening measures in reducing the risk factors of cardiovascular diseases $(14,15)$, many patients do not have sufficient knowledge of the relationship between a healthy lifestyle and CHD. As a result, the current study aimed at determining the relationship between a health-promoting lifestyle and its predictors among cardiovascular diseases.

\section{Material and methods}

This case-control study was conducted in 2015. After assessing all patients in terms of the eligibility criteria, the patients were given a short explanation about the study, and informed consent was obtained from all of the participants. The entry criteria included being willing to participate in the research, not having an emergency situation, and not having any speech and hearing problems. The sample of the study included 110 patients in each group (positive and negative exercise test) with $95 \%$ confidence level and $80 \%$ testable. We used the formula " $\mathrm{n}=$ $\left(\mathrm{z}_{1-\alpha / 2}+\mathrm{z}_{1-\beta}\right)^{2} / \mathrm{d}^{2}=(1.96+0.84)^{2} / 0.27^{2}=107.5 \cong 110$ " to determine the required sample size. Instruments used in this study were 1) a demographic questionnaire containing questions about age, gender, educational level, lodging, and employment status; 2) health-related variables, such as a history of hypertension, dyslipidemia, diabetes, and smoking; and 3) the Health Promoting Lifestyle-II (HPLP II) developed within the framework of the Health Promotion Model (8), which was used to measure the extent to which the individuals were engaging in healthpromoting and health-related behaviors (16). The 52-item Health-Promoting Lifestyles Profile-II (HPLP-II) was used to measure health-promoting behaviors. The items on this questionnaire include six subscales, i.e., 1) physical activity, which is concerned with the amount of exercise necessary for a healthy life; 2) spiritual growth, which is a person's positive attitude towards him/herself and the ability to improve her/his capabilities, and creativeness in reaching his/her objectives; 3) health responsibility, which is a person's sensitivity about her/his health; 4) interpersonal relationships, which are concerned with the ability to interact and maintain relationships with others; 5) nutrition, which relates to what one eats; and 6) stress management, which is the ability to identify what causes a person to feel stress and how he/she can overcome those causes (17). The Likert scale contains 1 (never) to 4 (routinely) as the responses to the items, and the total possible scores can range from 52 to 208. Higher scores suggest that the participants have healthier lifestyles. This questionnaire has been used extensively in medical research with high Cronbach's alpha coefficients to measure both the total scale and subscales $(16,18)$. The criteria of lifestyle categories were based on the first and third quarters. The first quarter's scores were considered as weak points, between the first and third quarters as medium, and the third quarter as high. The data were analyzed using IBM-SPSS version 22 and chi-squared, and logistic regression tests were used for analysis.

\section{Results}

The mean \pm SD age of the participants was $57.45 \pm 1.08$ in the experimental group and $58.75 \pm 1.11$ in the control group. There was no difference between demographic variable scores of positive and negative exercise stress test groups $(\mathrm{p}>0.05)$ (Table 1). The logistic regression model was used to determine the factors that affected positive exercise stress test. Positive exercise stress test was considered as the dependent variable, and gender, age, education, lodging, occupation, and marital status were considered as independent variables. Based on the logistic regression analyses, the risk of positive exercise stress test increased with age. The age group above 65 years was 1.049 times more at risk of positive exercise stress test compared with the age group of less than 45 (Table 2). Based on the logistic regression analyses, with the existence of hypertension and dyslipidemia, the risk of positive exercise stress test increased. So that, the people with dyslipidemia were 1.635 times more at risk of positive exercise stress 
tests than the group without dyslipidemia. In addition, the patients with hypertension were 1.579 times more at risk of positive exercise stress tests than the group without hypertension (Table 3). The highest risk of a positive exercise stress test was related to health responsibility. The people having poor responsibility for health were 1.622 times more at risk of positive exercise stress tests than people with high health responsibility. Those patients with lack of individual stress management (OR: 1.592) and physical activity (OR: 1.245) were more at risk of positive exercise tests (Table 4).

Table 1. Frequency distribution of patients in the two study groups

\begin{tabular}{|c|c|c|c|c|}
\hline \multirow{2}{*}{\multicolumn{2}{|c|}{ Demographic variables }} & \multirow{2}{*}{\multicolumn{2}{|c|}{ Study groups }} & p-value \\
\hline & & & & \\
\hline Age (years) & $<45$ & $\begin{array}{l}\text { Negative test } \\
22(20 \%)\end{array}$ & $\begin{array}{l}\text { Positive test } \\
27(24.54 \%)\end{array}$ & 0.069 \\
\hline & $45-65$ & $61(55.45 \%)$ & $64(58.18 \%)$ & \\
\hline & $>65$ & $27(24.54 \%)$ & $19(17.27 \%)$ & \\
\hline \multirow[t]{2}{*}{ Sex } & Male & $76(69.1 \%)$ & $79(71.8 \%)$ & \multirow[t]{2}{*}{0.384} \\
\hline & Female & $34(30.9)$ & $31(28.2 \%)$ & \\
\hline \multirow[t]{2}{*}{ Lodging } & City & $44(40 \%)$ & $53(48.2 \%)$ & \multirow[t]{2}{*}{0.139} \\
\hline & Village & $66(60 \%)$ & $57(51.8 \%)$ & \\
\hline \multirow[t]{3}{*}{ Educational Level } & Illiterate & $83(75.5 \%)$ & $80(72.7 \%)$ & \multirow[t]{3}{*}{0.814} \\
\hline & High school diploma & $22(20 \%)$ & $23(20.9 \%)$ & \\
\hline & Collegiate & $5(4.5 \%)$ & $7(6.4 \%)$ & \\
\hline \multirow[t]{6}{*}{ Occupation } & Homemaker & $69(62.7 \%)$ & $53(48.2 \%)$ & \multirow[t]{6}{*}{0.385} \\
\hline & Worker & $21(19.1 \%)$ & $27(24.2 \%)$ & \\
\hline & Retired & $9(8.2 \%)$ & $15(13.6 \%)$ & \\
\hline & Farmer & $4(3.6 \%)$ & $7(6.4 \%)$ & \\
\hline & Employee & $2(1.8 \%)$ & $2(1.8 \%)$ & \\
\hline & Freed & $5(4.5 \%)$ & $6(5.5 \%)$ & \\
\hline \multirow[t]{2}{*}{ Family history } & Yes & $45(40.9 \%)$ & $52(47.3 \%)$ & \multirow[t]{2}{*}{0.21} \\
\hline & No & $65(59.1 \%)$ & $58(52.7 \%)$ & \\
\hline \multirow[t]{2}{*}{ Smoking } & Yes & $31(28.2 \%)$ & $39(35.5 \%)$ & \multirow[t]{2}{*}{0.155} \\
\hline & No & $79(71.8 \%)$ & $71(64.5 \%)$ & \\
\hline
\end{tabular}

Table 2. Estimated logistic regression coefficients and odds ratios between demographic factors and exercise stress test

\begin{tabular}{|c|c|c|c|c|c|c|c|}
\hline \multirow{2}{*}{\multicolumn{2}{|c|}{ Demographic variables }} & \multirow{3}{*}{$\begin{array}{l}\text { B } \\
0.048\end{array}$} & \multirow{3}{*}{$\begin{array}{l}\text { S.E }{ }^{1} \\
0.179\end{array}$} & \multirow{3}{*}{$\begin{array}{l}\mathrm{OR}^{2} \\
1.049\end{array}$} & \multirow{2}{*}{\multicolumn{2}{|c|}{$95 \% \mathrm{CI}^{3}$ for $\mathrm{OR}$}} & \multirow{2}{*}{$\begin{array}{l}\text { p-value } \\
0.788\end{array}$} \\
\hline & & & & & & & \\
\hline Age (years) & $>65$ & & & & $\begin{array}{l}\text { Upper } \\
1.490\end{array}$ & $\begin{array}{l}\text { Lower } \\
0.739\end{array}$ & \\
\hline & $45-65$ & 0.521 & 0.290 & 0.594 & 1.047 & 0.337 & 0.042 \\
\hline & $<45$ & - & - & 1 & - & - & - \\
\hline \multirow[t]{2}{*}{ Sex } & Male & -0.065 & 0.161 & 0.938 & 1.285 & 0.684 & 0.688 \\
\hline & Female & - & - & 1 & - & - & - \\
\hline \multirow[t]{2}{*}{ Lodging } & City & 0.186 & 0.204 & 0.830 & 1.238 & 0.557 & 0.362 \\
\hline & Village & - & - & 1 & - & - & - \\
\hline \multirow[t]{3}{*}{ Educational level } & Illiterate & 0.037 & 0.157 & 1.037 & 1.410 & 0.763 & 0.814 \\
\hline & High school diploma & 0.044 & 0.298 & 0.957 & 1.716 & 0.533 & 0.822 \\
\hline & Collegiate & - & - & 1 & - & - & - \\
\hline \multirow[t]{6}{*}{ Occupation } & Homemaker & 0.264 & 0.183 & 1.302 & 1.862 & 0.910 & 0.149 \\
\hline & Worker & -0.251 & 0.291 & 0.778 & 1.376 & 0.440 & 0.388 \\
\hline & Retired & 0.511 & 0.422 & 0.600 & 1.371 & 0.263 & 0.226 \\
\hline & Farmer & -0.981 & 0.677 & 0.375 & 1.414 & 0.099 & 0.147 \\
\hline & Employee & 1.099 & 1.155 & 3.000 & 28.841 & 0.312 & 0.341 \\
\hline & Freed & - & - & 1 & - & - & - \\
\hline
\end{tabular}

1: Standard error, 2: Odds ratio, 3: Confidence interval 
Table 3. Estimated logistic regression coefficients and odds ratios between health factors and the results of exercise stress test

\begin{tabular}{|c|c|c|c|c|c|c|c|}
\hline \multirow{2}{*}{\multicolumn{2}{|c|}{ Health-related variables }} & \multirow{3}{*}{$\begin{array}{l}\text { B } \\
-0.186\end{array}$} & \multirow{3}{*}{$\begin{array}{l}\text { S.E } 1 \\
0.204\end{array}$} & \multirow{3}{*}{$\begin{array}{l}\mathrm{OR}^{2} \\
0.830\end{array}$} & \multicolumn{2}{|c|}{$95 \% \mathrm{CI}^{3}$ for $\mathrm{OR}$} & \multirow{3}{*}{$\begin{array}{l}p \text {-value } \\
0.362\end{array}$} \\
\hline & & & & & Upper & Lower & \\
\hline \multirow[t]{2}{*}{ Family history } & Yes & & & & 1.238 & 0.557 & \\
\hline & No & - & - & 1 & - & - & 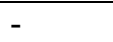 \\
\hline \multirow[t]{2}{*}{ Smoking } & Yes & -0.172 & 0.240 & 0.842 & 1.348 & 0.526 & 0.474 \\
\hline & No & - & - & 1 & - & - & - \\
\hline \multirow[t]{2}{*}{ Hypertension } & Yes & 0.547 & 0.243 & 1.579 & 2.932 & 0.359 & 0.024 \\
\hline & No & - & - & 1 & - & - & - \\
\hline \multirow[t]{2}{*}{ Diabetes } & Yes & -0.504 & 0.301 & 0.604 & 1.809 & 0.335 & 0.094 \\
\hline & No & - & - & 1 & - & - & - \\
\hline \multirow[t]{2}{*}{ Dyslipidemia } & Yes & 0.491 & 0.238 & 1.635 & 2.604 & 1.026 & 0.039 \\
\hline & No & - & - & 1 & - & - & - \\
\hline
\end{tabular}

1: Standard error, 2: Odds ratio, 3: Confidence interval

Table 4. Results of logistic regression analysis for examining the relationship between lifestyle factors and exercise test results

\begin{tabular}{|c|c|c|c|c|c|c|c|}
\hline \multicolumn{2}{|l|}{ Lifestyle factors } & \multirow{3}{*}{$\begin{array}{l}\text { B } \\
0.448 \\
\end{array}$} & \multirow{3}{*}{$\begin{array}{l}\text { S.E }{ }^{1} \\
0.190 \\
\end{array}$} & \multirow{3}{*}{$\begin{array}{l}\mathrm{OR}^{2} \\
1.622 \\
\end{array}$} & \multicolumn{2}{|c|}{$95 \% \mathrm{CI}^{3}$ for $\mathrm{OR}$} & \multirow{3}{*}{$\begin{array}{l}p \text {-value } \\
0.011\end{array}$} \\
\hline & & & & & \multirow{2}{*}{$\begin{array}{l}\text { Upper } \\
2.352\end{array}$} & \multirow{2}{*}{$\begin{array}{l}\text { Lower } \\
1.119\end{array}$} & \\
\hline Health & Weak & & & & & & \\
\hline responsibilities & Medium & -4.143 & 1.008 & 0.016 & 0.114 & 0.002 & 0.001 \\
\hline & Good & - & - & 1 & - & - & - \\
\hline \multirow[t]{3}{*}{ Physical activity } & Weak & 0.219 & 0.192 & 1.245 & 1.813 & 0.855 & 0.254 \\
\hline & Medium & -4.043 & 1.009 & 0.018 & 0.127 & 0.002 & 0.001 \\
\hline & Good & - & - & 1 & - & - & - \\
\hline \multirow[t]{3}{*}{ Dietary habits } & Weak & 0.090 & 0.245 & 1.094 & 1.766 & 0.677 & 0.714 \\
\hline & Medium & -0.095 & 0.195 & 0.909 & 1.333 & 0.620 & 0.626 \\
\hline & Good & - & - & 1 & - & - & - \\
\hline \multirow[t]{3}{*}{ Spiritual growth } & Weak & 0.159 & 0.253 & 1.172 & 1.924 & 0.714 & 0.529 \\
\hline & Medium & -0.199 & 0.191 & 0.820 & 1.191 & 0.564 & 0.297 \\
\hline & Good & - & - & 1 & - & - & - \\
\hline \multirow{3}{*}{$\begin{array}{l}\text { Individual } \\
\text { communication }\end{array}$} & Weak & -0.040 & 0.200 & 0.961 & 2.410 & 0.649 & 1.422 \\
\hline & Medium & -0.182 & 0.247 & 0.833 & 2.448 & 0.513 & 1.353 \\
\hline & Good & - & - & 1 & - & - & - \\
\hline \multirow[t]{3}{*}{ Stress management } & Weak & 0.465 & 0.182 & 1.592 & 2.275 & 1.114 & 0.011 \\
\hline & Medium & -4.060 & 1.009 & 0.017 & 0.124 & 0.002 & 0.001 \\
\hline & Good & - & - & 1 & - & - & - \\
\hline
\end{tabular}

1: Standard error, 2: Odds ratio, 3: Confidence interval

\section{Discussion}

This study was conducted to determine the effects of health-related variables and predictors of a health-promoting lifestyle in patients with cardiovascular disease. In this study, based on the logistic regression analyses, the risk of positive exercise stress test increased with age. Several reports (19-23) have defined the relationship between age and occurrence of coronary artery events. It seems that by ageing, the accumulation of plague atherosclerosis increased the possibility of coronary events and the severity of coronary artery diseases. Although most cardiovascular diseases are known as diseases of the elderly, almost $50 \%$ of the diagnoses and $15 \%$ of cardiovascular deaths occurred under the age of 60 (24). In Doughty's 2002 study, $10 \%$ of patients who had been hospitalized because of heart attacks over a three-year old period were under the age of 46 (25). Thus, it can be inferred that the age at which cardiovascular disease occurs has decreased, which is suggestive of our need for major lifestyle alterations in teenage and middle age population. Our findings showed that hypertension and dyslipidemia independently predicted risk of positive exercise stress test. Some studies (26-29) have reported hypertension as an independent risk factor for the severity of coronary artery disease. For instance, the study by Abbasi in 2012 was the closest to our results, reporting that hypertension was related to heart disease and coronary artery stenosis (OR: 3.45 , 
95\% CI: 3.28-3.61) (30). Also, in Armstrong's 2013 study that was conducted to evaluate the relative contribution of modifiable cardiovascular risk factors to the development of major cardiac events in aging adult survivors of childhood cancer, hypertension significantly increased the risk for coronary artery disease (RR: 6.1) (31). However, in Veeranna's 2010 study, hypertension did not correlate with coronary artery disease (22). This contradiction can be due to the various factors, such as target population, sample size, and the geographical location. In this study, dyslipidemia was reported as an independent risk factor for positive exercise stress test. Various studies (21, 28, 30, 32) have shown that dyslipidemia plays an important role in coronary artery disease. For example in Sadeghi's 2012 (26) and Rasheed's 2014 (27) studies, dyslipidemia was significantly associated with the extent and intensity of coronary stenosis. The results of Varbo's 2013 study showed that the increase of $1 \mathrm{mmol} / \mathrm{L}(39 \mathrm{mg} / \mathrm{dL})$ (LDL) increased the risk of ischemic heart disease as much as 2.8 times (33). In a study, Berry 2012 observed marked differences in the lifetime risks of cardiovascular disease among participants who were 55 or older, those with an optimal risk-factor profile (total cholesterol level, $<180 \mathrm{mg}$ per deciliter [4.7 mmol per liter]; blood pressure, $<120$ $\mathrm{mmHg}$ systolic and $80 \mathrm{mmHg}$ diastolic; nonsmoking status; and non-diabetic status) had substantially lower risks of death from cardiovascular disease through the age of 80 than participants with two or more major risk factors (34). The results are in line with our findings. Without doubt, the lack of physical activity and an unhealthy lifestyle result in obesity, hypertension, diabetes, and cardiovascular diseases. The researchers believe that modifying one's lifestyle may contribute to reducing obesity and hypertension and may reduce the risk of cardiovascular diseases (35-37). Therefore, this implies the vital role that a healthy lifestyle plays in reducing cardiovascular diseases, and it emphasizes the necessity to become more engaged in this matter. The comparison of the results of the study in terms of patients' lifestyles indicated that health responsibility, physical activity, and stress management affect the positive exercise stress test. The results of Mansourian's 2012 study showed that there was a significant relationship between responsibility, physical activity, stress management and hypertension (38). In Khairkhou's 2013 study on the lifestyle of women with rheumatoid arthritis, there was a significant relationship between two groups (healthy women and women with rheumatoid arthritis) with respect to two factors, i.e., responsibility for health and physical activity, which can be due to the nature of disease (39). Physical activity has always been the main intervening factor in reducing of heart disease. The results of Nagi's 2011 study showed that people who do physical activities regularly have less cholesterol, triglycerides, and blood pressure and also have a more appropriate Body Mass Index (BMI) (40). This study had some limitations. The data were collected through a self-report questionnaire, which may possibly tempt the participants to present a more desirable image of themselves. Moreover, participants may tend to overestimate or underestimate their health-promotion activity.

\section{Conclusions}

As the main finding of this study, it was indicated that there is a significant relationship between hypertension, dyslipidemia, and increasing age and the risk of positive exercise stress test and coronary artery stenosis. Also, having a healthy lifestyle brings some consequences that lead the patients of cardiovascular diseases to have positive health outcomes. It seems that educational interventions can improve the responsibility for health, physical activity, and stress management among people with cardiovascular disease risks. Therefore, there is an urgent need for the development and implementation of health education programs to raise health literacy and enhance people's knowledge concerning the risk factors of heart disease and to encourage them to adopt a health promotion lifestyle. It is recommended that further research be conducted on this significant issue to discover other effective factors that could lead to improved physical, psychological, and social condition of patients.

\section{Acknowledgments:}

We thank all of the patients who participated in this study. We also thank the managers, supervisors, and nursing staff at Mazandaran Heart Center Hospital for their input, suggestions, and guidance. This reports is part of a Ph.D. thesis in the field of Health Education and Promotion at the International campus of Tehran University of Medical Sciences with the code IRCT2015001248742N6 (Grant ID: 28217).

\section{Conflict of Interest:}

There is no conflict of interest to be declared.

\section{Authors' contributions:}

All authors contributed to this project and article equally. All authors read and approved the final manuscript.

\section{References:}

1) Truelsen $T$, Mähönen $M$, Tolonen $H$, Asplund $K$, Bonita R, Vanuzzo D. Trends in stroke and coronary heart disease in the WHO MONICA Project. Stroke. 2003; 34(6): 1346-52. doi: 10.1161/01.STR.0000069724.36173.4D, PMID: 12738889. 
2) Abegunde DO, Mathers CD, Adam T, Ortegon M, Strong K. The burden and costs of chronic diseases in low-income and middle-income countries. The Lancet. 2007; 370(9603): 1929-38. doi: 10.1016/S01406736(07)61696-1.

3) Hatmi Z, Tahvildari S, Motlag AG, Kashani AS. Prevalence of coronary artery disease risk factors in Iran: a population based survey. BMC Cardiovasc Disord. 2007; 7(1): 32. doi: 10.1186/1471-2261-7-32, PMID: 17971195, PMCID: PMC2200651.

4) i bl Di N. Noncommunicable Diseases Country Profiles 2011. World Health Organization 2011. Available from: http://www.un.org/en/ga/ncdmeeting2011/pdf/ncd_profiles_report.pdf

5) Liu K, Daviglus ML, Loria CM, Colangelo LA, Spring B, Moller AC, et al. Healthy Lifestyle Through Young Adulthood and the Presence of Low Cardiovascular Disease Risk Profile in Middle Age The Coronary Artery Risk Development in (Young) Adults (CARDIA) Study. Circulation. 2012; 125(8): 9961004. doi: 10.1161/CIRCULATIONAHA.111.060681, PMID: 22291127, PMCID: PMC3353808.

6) El mokadem NM. Health Promoting Lifestyle Behaviors among Women at High Risk for Cardiovascular Diseases. The Medical Journal of Cairo University. 2013; 81(2).

7) WHO. Milestones in health promotion: Statements from global conferences: Geneva: World Health Organization; 2009.

8) Pender N, Murdaugh C, Parsons M. The health promotion model. Health promotion in nursing practice. 2002; 4: 59-79.

9) Elmer PJ, Obarzanek E, Vollmer WM, Simons-Morton D, Stevens VJ, Young DR, et al. Effects of comprehensive lifestyle modification on diet, weight, physical fitness, and blood pressure control: 18month results of a randomized trial. Ann Intern Med. 2006; 144(7): 485-95. doi: 10.7326/0003-4819-144-7200604040-00007, PMID: 16585662.

10) Nissen SE, Tuzcu EM, Schoenhagen P, Crowe T, Sasiela WJ, Tsai J, et al. Statin therapy, LDL cholesterol, C-reactive protein, and coronary artery disease. $\mathrm{N}$ Engl J Med. 2005; 352(1): 29-38. doi: 10.1056/NEJMoa042000, PMID: 15635110

11) Wilt TJ, Bloomfield HE, MacDonald R, Nelson D, Rutks I, Ho M, et al. Effectiveness of statin therapy in adults with coronary heart disease. Arch Intern Med. 2004; 164(13): 1427-36. doi: 10.1001/archinte.164.13.1427, PMID: 15249352.

12) Chiuve SE, McCullough ML, Sacks FM, Rimm EB. Healthy lifestyle factors in the primary prevention of coronary heart disease among men benefits among users and nonusers of lipid-lowering and antihypertensive medications. Circulation. 2006; 114(2): 160-7. doi: 10.1161/CIRCULATIONAHA.106.621417, PMID: 16818808.

13) Daga MK, Zolfaghari R, Shahamfar M, Shahamfar J, Aslanabadi N, Gupta VK. Reduction of Risk Factors following Lifestyle Modification Programe in Patients with Coronary Heart Disease. JIMSA. 2010; 23(2): 73-74.

14) Van Limpt PM, Harting J, van Assema P, Ruland E, Kester A, Gorgels T, et al. Effects of a brief cardiovascular prevention program by a health advisor in primary care; the 'Hartslag Limburg' project, a cluster randomized trial. Prev Med. 2011; 53(6): 395-401. doi: 10.1016/j.ypmed.2011.08.031, PMID: 21925203.

15) Lieber SB, Redberg RF, Blumenthal RS, Gandhi A, Robb KJ, Mora S. A national interactive web-based physical activity intervention in women, evaluation of the American Heart Association choose to move program 2006-2007. Am J Cardiol. 2012; 109(12): 1754-60. doi: 10.1016/j.amjcard.2012.02.017, PMID: 22494850.

16) Walker S, Sechrist K, Pender N. The health-promoting lifestyle profile II. 1995.

17) Walker SN, Sechrist KR, Pender NJ. The health-promoting lifestyle profile: development and psychometric characteristics. Nurs Res. 1987; 36(2): 76-81. doi: 10.1097/00006199-198703000-00002, PMID: 3644262.

18) Acton GJ, Malathum P. Basic need status and health-promoting self-care behavior in adults. Western J Nurs Res. 2000; 22(7): 796-811. doi: 10.1177/01939450022044764.

19) Hosseini SA, Salehi A .The relationship between coronary risk factors and coronary artery involvement based on angiogrpahy findings. Koomesh. 2012; 14(1): 7-12.

20) Bidel Z, Nazarzadeh M. Evaluating the Associations between Some Cardiovascular Risk Factors and Coronary Artery Obstruction Based on Angiographic Findings. Scientific Journal of Ilam University of Medical Sciences. 2014; 22(1): 147-54.

21) Darabian S, Abbasi A .The correlation of ischemic risk factors with left main tract disease. KAUMS Journal (FEYZ). 2007; 11(3): 31-5. 
22) Veeranna V, Pradhan J, Niraj A, Fakhry H, Afonso L. Traditional cardiovascular risk factors and severity of angiographic coronary artery disease in the elderly. Prev Cardiol. 2010; 13(3): 135-40. PMID: 20626669.

23) Camargo GC, Rothstein T, Derenne ME, Sabioni L, Calafate IR, Xavier CA, et al. Factors Associated With Coronary Artery Disease Progression Assessed by Serial Coronary Computed Tomography Angiography. Circulation. 2013; 128(22 Suppl): A11576.

24) Lloyd-Jones D, Adams RJ, Brown TM, Carnethon M, Dai S, De Simone G, et al. Heart disease and stroke statistics - 2010 update A report from the American Heart Association. Circulation. 2010; 121(7): e46e215. doi: 10.1161/CIRCULATIONAHA.109.192667, PMID: 20019324.

25) Doughty M, Mehta R, Bruckman D, Das S, Karavite D, Tsai T, et al. Acute myocardial infarction in the young-The University of Michigan experience. American heart journal. 2002; 143(1): 56-62. doi: 10.1067/mhj.2002.120300, PMID: 11773912.

26) Sadeghi M, Pourmand K, Sanei H, Heidari R, Talaei M. Which major atherosclerosis risk factors represents the extent of coronary artery disease? ARYA Atheroscler. 2012; 7: S63-S9.

27) Rasheed A, Habib S, Dar MI, Jahan N. Effect of risk factors like age, gender, hypertension, diabetes, smoking, dyslipidemia on coronary artery disease in Karachiites with angiographical data of local population: Number, site, severity of coronary lesion. Pakistan journal of pharmaceutical sciences. 2014; 27(6).

28) Schenck-Gustafsson K. Risk factors for cardiovascular disease in women. Maturitas. 2009; 63(3): 186-90. doi: 10.1016/j.maturitas.2009.02.014, PMID: 19403246.

29) Hossain S. TCTAP A-163 Association of Hypertension on Development of Coronary Collaterals in Severe Coronary Artery Disease. J Am Coll Cardiol. 2015; 65(17_S): S76-S. doi:10.1016/j.jacc.2015.03.244.

30) Abbasi S, De Leon AP, Kassaian S, Karimi A, Sundin Ö, Soares J, et al. Gender differences in the risk of coronary artery disease in Iran. Iranian journal of public health. 2012; 41(3): 36.

31) Armstrong GT, Oeffinger KC, Chen Y, Kawashima T, Yasui Y, Leisenring W, et al. Modifiable risk factors and major cardiac events among adult survivors of childhood cancer. J Clin Oncol . 2013: JCO. 2013.49. 3205.

32) Guo Y, Zhang W, Zhou Y, Zhao D, Zhou Z, Zhang H. [Study of the relationship between cardiovascular risk factors and severity of coronary artery disease in patients underwent coronary angiography]. Zhonghua xin xue guan bing za zhi. 2005; 33(5): 415-8. PMID: 15932697.

33) Varbo A, Benn M, Tybjaerg-Hansen A, Jørgensen AB, Frikke-Schmidt R, Nordestgaard BG. Remnant cholesterol as a causal risk factor for ischemic heart disease. J Am Coll Cardiol. 2013; 61(4): 427-36. doi: 10.1016/j.jacc.2012.08.1026, PMID: 23265341.

34) Berry JD, Dyer A, Cai X, Garside DB, Ning H, Thomas A, et al. Lifetime risks of cardiovascular disease. N Engl J Med. 2012; 366(4): 321-9. doi: 10.1056/NEJMoa1012848, PMID: 22276822, PMCID: PMC3336876.

35) Monasta L, Batty G, Cattaneo A, Lutje V, Ronfani L, Van Lenthe F, et al. Early - life determinants of overweight and obesity: a review of systematic reviews. Obesity Reviews. 2010; 11(10): 695-708. doi: 10.1111/j.1467-789X.2010.00735.x, PMID: 20331509.

36) Wilson PW, D'Agostino RB, Sullivan L, Parise H, Kannel WB. Overweight and obesity as determinants of cardiovascular risk: the Framingham experience. Arch Intern Med. 2002; 162(16): 1867-72. doi: 10.1001/archinte.162.16.1867, PMID: 12196085

37) Rivera JÁ, de Cossío TG, Pedraza LS, Aburto TC, Sánchez TG, Martorell R. Childhood and adolescent overweight and obesity in Latin America: a systematic review. The Lancet Diabetes \& Endocrinology. 2014; 2(4): 321-32. doi: 10.1016/S2213-8587(13)70173-6.

38) Mansoorian M, Qorbani M, Shafieyan N, Asayesh H, Shafieyan Z, Maghsodloo D. Association between life style and hypertension in rural population of Gorgan. Journal of Health Promotion Management. 2012; 1(2): 23-8.

39) Kheirjoo E, Jomehri F, Ahadi H, Manisefat FF. Comparison of Health Promoting Lifestyle of Female Rheumatoid Arthritis Patients with Healthy Women and It's Relationship with Demographic Factors. Knowledge \& Research In Applied Psychology. 2013; 13(4): 61-70.

40) Naghii M, Almadadi M. Effect of regular physical activity as a basic component of lifestyle modification on reducing major cardiovascular risk factors. Knowledge \& Health. 2011; 6(1): 27-35. 